\title{
The level of microRNA 21 is upregulated by rapamycin in serum of tuberous sclerosis complex patients and subependymal giant cell astrocytoma (SEGA)-derived cell cultures
}

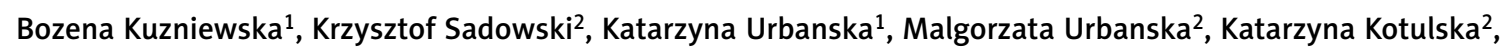 \\ Ewa Liszewska ${ }^{3}$, Wieslawa Grajkowska ${ }^{4}$, Sergiusz Jozwiak ${ }^{2,5}$, Magdalena Dziembowska ${ }^{1}$ \\ ${ }^{1}$ Centre of New Technologies, University of Warsaw, Warsaw, ${ }^{2}$ Department of Neurology and Epileptology, The Children's Memorial \\ Health Institute, Warsaw, ${ }^{3}$ Laboratory of Molecular and Cellular Neurobiology, International Institute of Molecular and Cell Biology, \\ Warsaw, ${ }^{4}$ Department of Experimental and Clinical Neuropathology, Mossakowski Medical Research Centre, Polish Academy \\ of Sciences, Warsaw, ${ }^{5}$ Department of Pediatric Neurology, Medical University of Warsaw, Warsaw, Poland
}

\begin{abstract}
Tuberous sclerosis complex (TSC) represents a genetic condition, in which the clinical manifestations are caused by the disinhibition of the mammalian target of rapamycin (mTOR) pathway due to mutations in the TSC1 (hamartin) or TSC2 (tuberin) genes. The deregulated MTOR activity leads to multi-site tumors, including subependymal giant cell astrocytoma (SEGA). SEGA is a brain tumor that affects around 15\% of TSC patients. The aim of the study was to evaluate miR-21 expression in the serum of two groups of TSC patients: with or without SEGA tumors. We found no differences in the level of miR-21 depending on the presence of SEGA. Next, we studied the influence of prolonged rapamycin administration on miR-21 level in the blood serum of TSC patients (6-12 months of rapamycin) and in primary cultures of SEGA-derived cells treated with rapamycin in vitro. Here we show that rapamycin treatment leads to the upregulation of miR-21 in both patients' serum and in primary SEGA tumor cells in the culture indicating the regulatory relationship between rapamycin treatment and miR-21 expression.
\end{abstract}

Key words: tuberous sclerosis, SEGA, miR-21, rapamycin.

\section{Introduction}

Tuberous sclerosis complex (TSC) is an autosomal dominant disorder caused by loss-of-function mutations in the TSC1 (hamartin) or TSC2 (tuberin) genes. TSC1 and TSC2 form the TSC protein complex that acts as an inhibitor of the mammalian target of rapamycin (mTOR) pathway - a master regulator of cell growth, proliferation, protein synthesis and autophagy [10]. Hyperactive mTOR signaling leads to the unregulated cell growth that are among clinical symptoms of the disease: tumors of different

\footnotetext{
Communicating authors

Magdalena Dziembowska, PhD, Centre of New Technologies, University of Warsaw, 2C Banacha St., 02-097 Warsaw, Poland, e-mail: m.dziembowska@cent.uw.edu.pl

Prof. Sergiusz Jóźwiak, Department of Neurology and Epileptology, The Children's Memorial Health Institute, Warsaw, Department of Pediatric Neurology, Medical University of Warsaw, Warsaw, Poland, e-mail: sergiusz.jozwiak@gmail.com
} 
organs, including the brain, kidneys, lung and heart [4]. Subependymal giant cell astrocytoma (SEGA) is a common brain tumor found in $12-15 \%$ of the TSC patients [5,7].

In the last few years, mTOR inhibitors have been approved for the treatment of many manifestations of TSC including brain SEGAs, renal angiomyolipomas (AML) and pulmonary lymphangioleiomyomatosis (LAM) [4,14-16]. Clinical trials have demonstrated that rapamycin-based therapy induces the tumor regression, however due to the cytostatic and not cytotoxic properties of rapamycin, the tumors regrow upon the cessation of the treatment $[1,3]$ Thus, current treatment strategies focus on combining rapamycin with other drugs such as bioavailable antagomiRs targeting miR-21 [9,10].

MicroRNA 21 (miR-21) has been found to be upregulated in almost all types of cancers and therefore was classified as an oncomiR [8]. On the other hand, it has been found to be one of the rapamycin-dependent miRs, induced by rapamycin treatment in vitro in different cell types [17]. Recently, it has been shown that miR-21 inhibition may repress the tumor growth of TSC2-/- xenografts in mice [9]. However the effect of rapamycin treatment of TSC patients on miR-21 expression has not been studied so far.

\section{Material and methods \\ Patients}

miR-21-5p expression profiling was performed in a single-center group of twenty eight TSC patients, children and young adults, from an in- and outpatient clinic in the Department of Neurology and Epileptology; Children's Memorial Health Institute. All individuals fulfilled current clinical criteria for definite TSC [11]. In 14 patients, the disease was confirmed with genetic tests. In this group, 10 patients presented with TSC2 gene mutation, whereas 4 patients had TSC 1 mutation. Four individuals had PKD1/TSC2 contiguous gene syndrome. Fifteen patients were diagnosed with subependymal giantcell astrocytoma defined as a lesion at the caudothalamic groove with either a size of more than $1 \mathrm{~cm}$ in any direction or a subependymal lesion at any location that has shown serial growth on consecutive imaging regardless of the size. Avid enhancement after contrast administration was assessed, however, a growing subependymal lesion even in the absence of enhancement was consid- ered a SEGA $[6,12]$. Nine patients were treated with mTOR pathway inhibitor-rapamycin (Rapamune, Pfizer). Serum drug concentrations were titrated to obtain therapeutic values of $5-10 \mathrm{ng} / \mathrm{ml}$. Basic demographic data and clinical features of patients are summarized in Tables I and II. Written informed consent was given by the caregivers before rapamycin treatment was introduced. Separate informed consent was obtained for the purpose of this study for all 28 participants. This research was performed in the accordance with the Declaration of Helsinki and accepted by the Bioethical Committee in the Children's Memorial Health Institute in Warsaw.

\section{RNA extraction and cDNA synthesis}

Serum samples were obtained from TSC patients using standard vials with clotting activator (S-Monovette $^{\circledR} 2.7 \mathrm{ml}$ ). After clot formation, samples were centrifuged at $2500 \mathrm{rpm}$ for $10 \mathrm{~min}$. Afterwards, serum was collected and stored at $-80^{\circ} \mathrm{C}$ until testing. Total RNA including the miRNA fraction was isolated from $200 \mu$ of serum samples using miRCURY RNA Isolation Kit - Biofluid (Exiqon) according to the manufacturer's instructions. Purified RNA was eluted in $50 \mu \mathrm{l}$ of $\mathrm{H}_{2} \mathrm{O}$. Equal volume of each RNA sample $(4 \mu \mathrm{l})$ was reverse transcribed in $20 \mu \mathrm{l}$ RT reaction using miRCURY LNA Universal RT microRNA PCR Universal cDNA Synthesis Kit II (Exiqon, 203301) according to the manufacturer's instructions.

\section{Quantitative real-time PCR}

Quantitative real-time PCR ( $q R T-P C R$ ) reactions were performed using ExiLENT SYBR Green Master Mix Kit (Exiqon) in the LightCycler480 real-time PCR system (Roche) using the following cycling conditions: $95^{\circ} \mathrm{C}$ for $10 \mathrm{~min}$, followed by 45 cycles of $95^{\circ} \mathrm{C}$ for $10 \mathrm{~s}$ and $60^{\circ} \mathrm{C}$ for $1 \mathrm{~min}$. CDNA template was diluted $40 \times$ in nuclease-free water for the qRT-PCR analysis as recommended by the manufacturer. The following primer sets (miRCURY LNA UniRT PCR primer mix, Exiqon) were used: hsa-miR-21-5p (204230), hsa-miR-103a$3 p$ (204063), and hsa-miR-423-3p (204488). Specificity of the primers was determined using melt curve analysis. Fold changes in the expression were determined using the $\Delta \Delta C T$ relative quantification method. Two different endogenous control primer sets were used - values were normalized to the relative amounts of miR-103a-3p and miR-423-3p. 
Table I. Demographic, clinical and genetic characteristics of the study group of patients with TSC

\begin{tabular}{|c|c|c|c|c|c|c|c|c|c|c|}
\hline $\begin{array}{l}\text { Sex } \\
(\mathrm{F} / \mathrm{M})\end{array}$ & Age & Mutation & $\begin{array}{l}\text { SEGA } \\
\text { tumors }\end{array}$ & $\begin{array}{c}\text { \# of } \\
\text { SEGA } \\
\text { lesions }\end{array}$ & Epilepsy & $\begin{array}{l}\text { Antiepileptic } \\
\text { drugs }\end{array}$ & ID & Skin lesions & $\begin{array}{l}\text { Renal } \\
\text { lesions }\end{array}$ & Other features \\
\hline $\mathrm{F}$ & 1 & TSC2 & - & - & Y & VGB, VPA & $\mathrm{N}$ & HM & cysts & \\
\hline $\mathrm{F}$ & 1 & nt & - & - & Y & VGB & N & HM & - & \\
\hline M & 2 & TSC2 & - & - & Y & VGB, VPA, LEV & N & $A F, H M$ & cysts & \\
\hline $\mathrm{F}$ & 5 & $\mathrm{nt}$ & - & - & Y & VPA, OXC & N & $A F, H M$ & cysts, AML & \\
\hline $\mathrm{F}$ & 14 & $\mathrm{TSC1}$ & - & - & $\mathrm{N}$ & N/A & $\mathrm{N}$ & $\mathrm{AF}$ & $\mathrm{AML}$ & liver AML \\
\hline $\mathrm{F}$ & 16 & $\mathrm{TSC1}$ & - & - & N & $\mathrm{N} / \mathrm{A}$ & N & $\mathrm{AF}$ & $\begin{array}{l}\text { cysts, large } \\
\text { AML }\end{array}$ & \\
\hline $\mathrm{F}$ & 35 & TSC2 & - & - & N & N/A & N & $A F$ & cysts & \\
\hline $\mathrm{F}$ & 32 & $\mathrm{nt}$ & - & - & N & N/A & N & - & - & \\
\hline$M$ & 46 & nt & - & - & N & $\mathrm{N} / \mathrm{A}$ & N & $\mathrm{AF}$ & - & \\
\hline$M$ & 36 & $\mathrm{nt}$ & - & - & $\mathrm{N}$ & N/A & $\mathrm{N}$ & $\mathrm{AF}$ & AML & liver AML \\
\hline M & 41 & $\mathrm{TSC} 2$ & - & - & N & N/A & $\mathrm{N}$ & - & - & \\
\hline $\mathrm{F}$ & 35 & $\mathrm{nt}$ & - & - & $\mathrm{N}$ & N/A & $\mathrm{N}$ & - & - & \\
\hline $\mathrm{F}$ & 36 & TSC1 & - & - & N & N/A & $\mathrm{N}$ & $\mathrm{AF}$ & - & \\
\hline$M$ & 1 & TSC2 & + & 1 & Y & VGB, VPA & $\mathrm{N}$ & $\mathrm{HM}$ & cysts, AML & \\
\hline M & 1 & $\begin{array}{l}\text { TSC2 + } \\
\text { PKD }\end{array}$ & + & 1 & Y & VGB, TPM, LTG & Y & $\mathrm{HM}$ & PKD & \\
\hline M & 3 & nt & + & 1 & Y & VGB, LEV & $\mathrm{N}$ & $\mathrm{HM}$ & cysts & \\
\hline M & 4 & $\begin{array}{c}\mathrm{TSC} 2+ \\
\text { PKD }\end{array}$ & + & 1 & Y & VGB, VPA, CLB & Y & HM & PKD & \\
\hline $\mathrm{F}$ & 5 & $\begin{array}{c}\text { TSC2 + } \\
\text { PKD }\end{array}$ & + & 1 & Y & VGB, LEV, LTG & Y & $A F, H M$ & PKD & $\begin{array}{c}\text { multiple cardiac } \\
\text { tumors }\end{array}$ \\
\hline M & 7 & nt & + & 1 & Y & VGB, VPA & N & $A F, H M, F P$ & cysts & $\begin{array}{c}\text { cardiac } \\
\text { rhabdomyoma }\end{array}$ \\
\hline M & 8 & NMI & + & 1 & Y & VGB & N & $\mathrm{AF}$ & - & \\
\hline M & 9 & nt & + & 1 & Y & VGB, VPA, LEV, TPM & Y & $\mathrm{AF}, \mathrm{HM}, \mathrm{FP}$ & $A M L$ & \\
\hline $\mathrm{F}$ & 10 & nt & + & 1 & $\mathrm{Y}$ & CBZ, LTG, VGB & $Y$ & $\mathrm{AF}, \mathrm{HM}$ & cysts, AML & \\
\hline $\mathrm{F}$ & 10 & TSC2 & + & 2 & Y & VGB, TPM, LEV & $Y$ & $\mathrm{AF}, \mathrm{HM}, \mathrm{SP}$ & AML & \\
\hline M & 11 & nt & + & 1 & Y & VGB, VPA, LEV, TPM & Y & $A F, H M, S P$ & cysts & $\begin{array}{c}\text { cardiac } \\
\text { rhabdomyoma }\end{array}$ \\
\hline M & 14 & nt & + & 2 & Y & CBZ & $\mathrm{N}$ & $\mathrm{AF}$ & cysts & \\
\hline M & 16 & $\begin{array}{c}\text { TSC2 + } \\
\text { PKD }\end{array}$ & + & 1 & Y & VGB, LEV & Y & $A F, H M, S P$ & PKD & \\
\hline $\mathrm{F}$ & 25 & TSC1 & + & 1 & N & N/A & $\mathrm{N}$ & $\mathrm{AF}$ & - & \\
\hline$M$ & 26 & nt & + & 1 & N & $N / A$ & N & AF & - & \\
\hline
\end{tabular}

nt - not tested; ID - intellectual disability; HM - hypomelanotic macules; AF-facial angiofibroma; FP - fibrous plaque; SP - shagreen patch; AML - angiomyolipoma; PKD - polycystic kidney disease; VGB - vigabatrin; VPA - valproate; LEV - levetiracetam; OXC - oxcarbazepine; TPM - topiramate; LTG - lamotrigine; $C L B$ - clobazam; CBZ - carbamazepine

\section{Primary SEGA cell cultures and treatment}

The tumors included in this study were obtained from the Department of Neurology and Epileptology, and the Department of Pathology, The Children's Memorial Health Institute in Warsaw. Primary
SEGA cell cultures were derived from surgical brain specimens obtained from TSC patients. Tissue was mechanically minced into smaller fragments and cultured in the incubation medium containing Dulbecco's modified Eagle's medium supplemented with 50 units $/ \mathrm{ml}$ penicillin, $50 \mu \mathrm{g} / \mathrm{ml}$ streptomycin and $10 \%$ fetal bovine serum in $37^{\circ} \mathrm{C}, 5 \% \mathrm{CO}_{2}$. Sparsely 
Table II. Demographic and clinical characteristics of the study group of TSC patients treated with rapamycin

\begin{tabular}{|ccccccccc|}
\hline $\begin{array}{c}\text { Sex } \\
(\mathrm{F} / \mathrm{M})\end{array}$ & Age & $\begin{array}{c}\text { \# of SEGA } \\
\text { lesions }\end{array}$ & ID & $\begin{array}{c}\text { Skin } \\
\text { lesions }\end{array}$ & Renal lesions & Epilepsy & $\begin{array}{c}\text { Antiepileptic drugs } \\
\text { given }\end{array}$ & $\begin{array}{c}\text { Rapamycin } \\
\text { (months) }\end{array}$ \\
\hline M & 2 & - & Y & AF, HM & - & Y & VGB & 6 \\
\hline F & 8 & - & Y & AF, HM & AML & Y & VGB & 6 \\
\hline F & 10 & - & N & AF, HM & AML & - & - & 6 \\
\hline M & 13 & - & Y & AF, HM & cysts, AML & - & - & 6 \\
\hline M & 13 & - & Y & AF, HM & cysts & Y & LTG, LEV, CBZ & 6 \\
\hline M & 14 & 1 & N & AF, HM & - & - & - & 6 \\
\hline F & 6 & 1 & N & AF, HM & - & Y & CBZ & 6 \\
\hline F & 14 & - & N & AF, HM & AML & - & - & 12 \\
\hline F & 16 & - & N & AF, HM & AML & - & - & 12 \\
\hline
\end{tabular}

ID - intellectual disability; AF - facial angiofibroma; HM - hypomelanotic macules; AML - angiomyolipoma; VGB - vigabatrin; LTG - lamotrigine; LEV - levetiracetam; $C B Z$ - carbamazepine

plated cells on glass coverslips coated with $0.2 \%$ gelatin were treated for $48 \mathrm{~h}$ with $100 \mathrm{nM}$ rapamycin or vehicle DMSO and fixed.

\section{Fluorescence in situ hybridization and immunodetection, image acquisition and analysis}

For the in situ hybridization and immunofluorescent staining cells were fixed with $4 \%$ paraformaldehyde that contained $4 \%$ sucrose in phosphate-buffered saline for $7 \mathrm{~min}$ at room temperature (RT). In situ hybridization for miR-21-5p was performed using the antisense oligonucleotide probes hsa-miR-21 (miRCURY LNA Detection probe, Exiqon). Briefly,

\section{A}

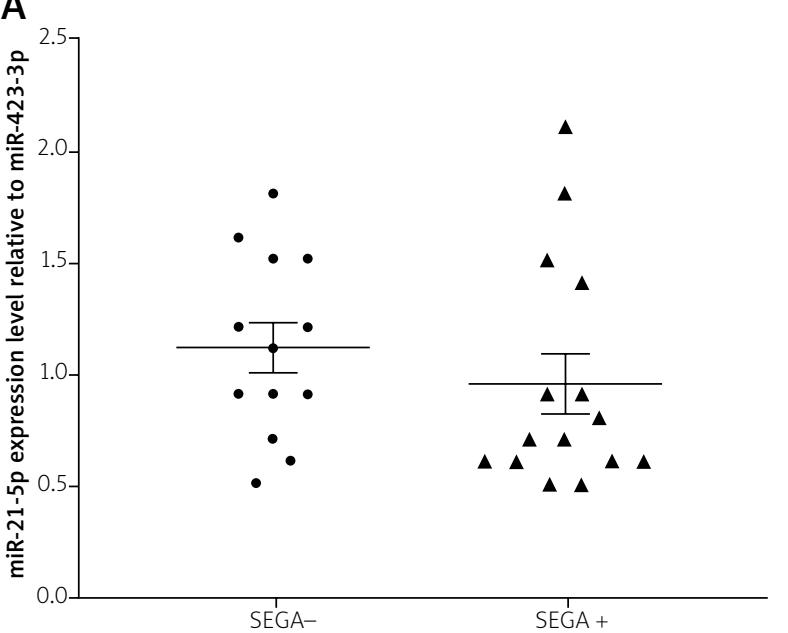

the fixed SEGA cells were washed in PBS, treated with $1 \% \mathrm{H}_{2} \mathrm{O}_{2}$ and acetylated with acetylation buffer $(0.1 \mathrm{M}$ triethanolamine, $0.25 \% \mathrm{HCl}, 0.25 \%$ acetic anhydride). The prehybridization solution with 50\% formamide (Sigma-Aldrich) was applied for $2 \mathrm{~h}$ and replaced with a hybridization solution (Sigma-Aldrich) with antisense riboprobes ( $15 \mathrm{nM}$ concentration) for overnight incubation in $53^{\circ} \mathrm{C}$. Next, the cells were washed three times with $0.5 \times$ saline-sodium citrate buffer (SSC) at $53^{\circ} \mathrm{C}$, three times with $0.2 \times$ SSC at $48^{\circ} \mathrm{C}$, twice with $0.2 \times$ SSC at RT and three times with PBS-Tween $0.1 \%$ (PBS-T) at RT. Then, the unspecific binding was blocked with $10 \%$ normal goat serum (NGS) in TNB blocking solution (TSA Plus

B

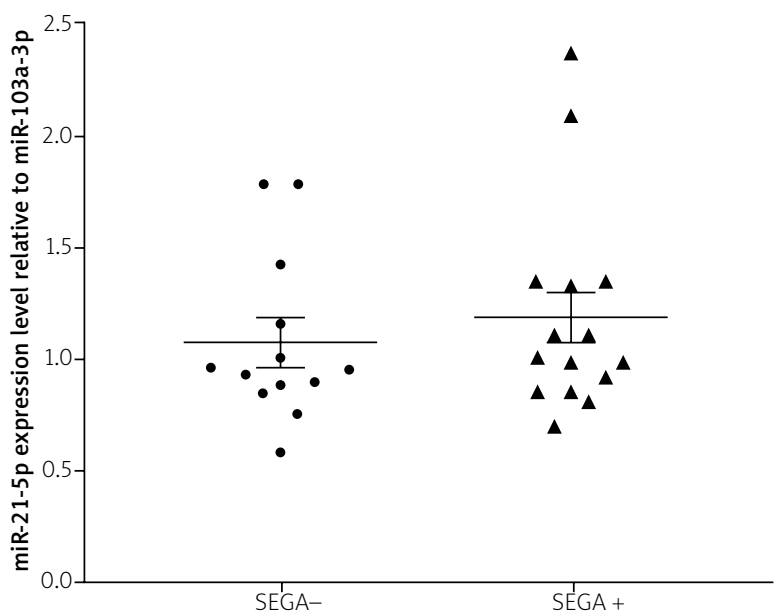

Fig. 1. The level of miR-21-5p in blood serum from SEGA negative $(n=13)$ and SEGA positive $(n=15)$ TSC patients (not significant, $p>0.05$; unpaired, two-tailed $t$-test). 
A

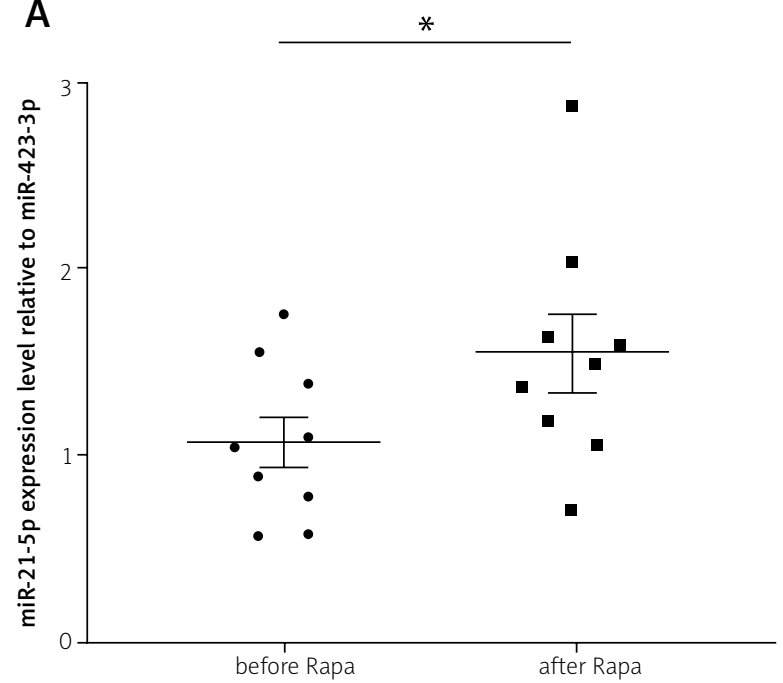

B

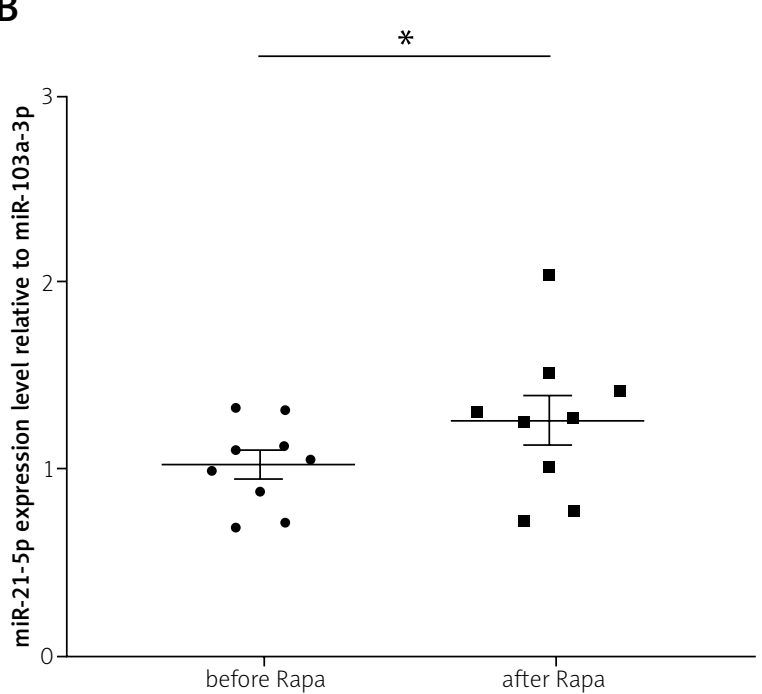

Fig. 2. The effect of 6-12 months of rapamycin treatment on miR-21-5p level in the blood serum of TSC patients $\left(n=9 ;{ }^{*} p<0.05\right.$, ratio paired $t$-test).

System; PerkinElmer) for 1 hat RT. The cells were incubated with anti-digoxigenin-POD $(1: 200$ in TNB, Roche) and rabbit anti-Phospho-S6 Ribosomal Protein antibody (1: 400 in TNB, \#4858S, Cell Signaling) in a humidified chamber overnight in $4^{\circ} \mathrm{C}$, next they were washed with PBS-T, and incubated with Alexa 488-conjugated anti-rabbit IgG secondary antibody (1 : 1000; Invitrogen). The hybridization signal was amplified with TSA Cy3 System (Perkin Elmer). The imaging was performed using confocal microscope LSM 700, Axio Imager Z2 (Zeiss) in a stack of $0.4 \mu \mathrm{m}$ thick $Z$ section, using a $40 \times$ objective (oil immersion; $1.3 \mathrm{NA}$ ) with 1.2 zoom factor. The obtained stack was "flattened" into a single image using a maximum intensity projection. Quantification of fluorescence signal intensity was performed in ImageJ software. Signal intensity was averaged on the cell area.

\section{Statistical analysis}

Relative abundance of miR-21-5p in the serum of SEGA- and SEGA+ TSC patients was compared using unpaired, two-tailed Student's $t$-test. The levels of miR-21-5p in serum of patients before and after rapamycin treatment was assessed using ratio-paired Student's $t$-test. The effect of rapamycin on miR-21$5 p$ expression and $\mathbf{S 6}$ phosphorylation status in primary cultured SEGA-derived cells was analyzed using unpaired, two-tailed Student's t-test. Statistical analysis was performed in GraphPad Prism (7.0).

\section{Results}

\section{Level of miR-21-5p in blood serum of TSC patients}

In the previous study, an increased expression of miR-21 was detected in cortical tubers of TSC patients [18]. Here, we examined the level of miR21-5p expression in the blood serum of TSC patients in two groups distinguished depending on the development of SEGA tumors. The serum obtained from 15 SEGA positive patients and 13 SEGA negative ones was analyzed. The clinical and genetic characteristics of patients with TSC are presented in Table I. The level of miR-21-5p expression was analyzed in each sample using miRCURY LNA UniRT microRNA PCR kit. Two microRNAs were used to normalize the results - miR-103a-3p and miR-423-3p, which are recommended as reliable reference genes for quantification of microRNAs in serum and plasma samples (Exiqon). There was no statistically significant difference in the serum level of miR-21-5p in SEGA positive and SEGA negative patients (Fig. 1).

\section{Level of miR-21-5p in blood serum of TSC patients before and after rapamycin treatment}

Rapamycin was shown to induce the expression of miR-21 in cellular models of TSC (TSC2-/- cell lines) and sporadic LAM [17]. We studied the effect 

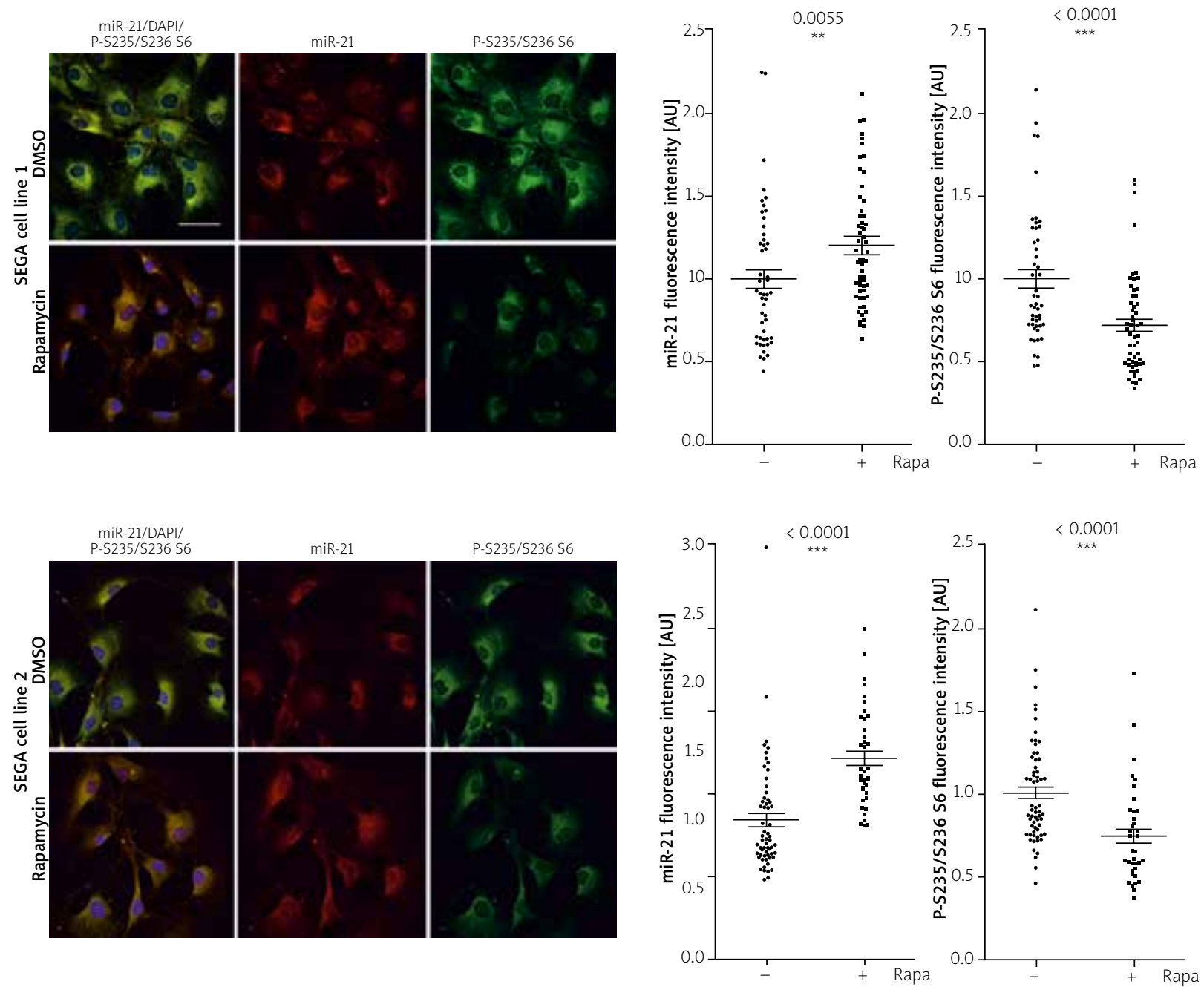

Fig. 3. MiR-21-5p expression in primary SEGA cell cultures derived from two different patients. The cells were treated with rapamycin $(100 \mu \mathrm{M})$ for 48 hours $\left({ }^{* *} p<0.01,{ }^{* * *} p<0.001\right.$, unpaired, two-tailed $t$-test).

of rapamycin administration on the miR-21-5p level in the blood serum of nine TSC patients: seven patients taking rapamycin for 6 months and two patients taking rapamycin for 12 months. Samples were collected before the initiation of the treatment and 6-12 months after the treatment. The expression of miR-21-5p was determined using qRT-PCR for miR-21-5p and two other microRNAs that served for normalization (miR103a-3p and miR423-3p). We observed a statistically significant miR-21-5p upregulation in the blood serum of TSC patients taking rapamycin (Fig. 2).

\section{Expression of miR-21-5p in primary cultured SEGA-derived cells treated with rapamycin}

MiR-21 expression was detected in SEGA tumor sections and was specifically increased in SEGA cells that were also positive for phospho-S6 [18]. However, the effect of rapamycin treatment on miR-21 expression in these cells was not studied.

To study the effect of rapamycin on miR-21-5p expression directly in SEGA cells we used the established primary SEGA cell cultures derived from 2 different patients. The cells were treated with rapamycin 
$(100 \mu \mathrm{M})$ for 48 hours. Next, the level of miR-21-5p expression was detected using the in situ hybridization with a specific probe. The intensity of miR21-5p fluorescence was measured in each cell and the effect of rapamycin was monitored by detection of the $\mathbf{S 6}$ phosphorylation status in the same cells. In SEGA cells from patients 1 and 2, we observed a significant downregulation of phospho-S6 level in response to rapamycin, as expected. Interestingly, in the same cells that exhibited S6 dephosphorylation, which is a hallmark of mTOR inhibition, we observed an increase in miR-21-5p level (Fig. 3). This was consistent with our data on serum samples (Fig. 2).

\section{Discussion}

MiR-21 has been shown to be overexpressed in most cancer types [8] and was classified as "oncomiR" due to its prosurvival effect on cancer cells through the inhibition of the tumor suppressor genes. Recently the upregulation of miR-21 has been observed in brain tubers of TSC patients [18] and in TSC2-deficient cells in vitro [9]. However, the role of miR-21 in TSC and SEGA tumors and the molecular mechanism involved is still underinvestigated.

In the current study we evaluated the levels of miR-21-5p in blood serum from TSC patients with or without SEGA tumors. We found no difference between the two groups of patients. Also, no differences were observed when patients were grouped according to age, presence or lack of the renal tumors, epilepsy and intellectual disability. These results show that although miR-21-5p is elevated in the brain tumors in TSC, the serum levels of miR21-5p seem not to be altered in TSC patients by the presence of SEGA.

Since mutations in TSC1 and TSC2 result in mTOR hyperactivity, inhibition of the MTOR pathway is one of the therapeutic strategies in TSC. Systemic treatment with mTOR inhibitors may effectively treat multiple manifestations of TSC, such as epilepsy, skin lesions, LAM, renal, brain and cardiac tumors [14] demonstrating a beneficial safety profile [13]. However, rapamycin and rapalogs induce only a cytostatic response, thus the tumors tend to regrow if the treatment is discontinued [3]. Moreover, there are few TSC patients, in whom the response to the rapamycin therapy is very poor [2]. It is possible that some compensatory effects exist that may be activated in response to chronic rapamycin treatment.
Mir-21 has been previously identified as one of the "RapamiRs" that were induced in vitro in cells treated with rapamycin [17]. Here, we demonstrate that a similar effect can be detected in vivo in blood serum from TSC patients. We found increased miR21-5p levels in serum of nine TSC patients after 6-12 months of rapamycin administration. Additionally, we verified that in primary SEGA cell cultures derived from two different TSC patients, rapamycin treatment led to downregulation of phosphos6 and upregulation of miR-21-5p expression. Together we have shown the elevated miR-21-5p levels in response to rapamycin in eleven available samples from TSC patients and we reckon that a larger cohort of patients would be required to further confirm the results.

Although it might seem awkward that an expression of miR-21-5p, that is an "oncomiR" elevated in brain tubers of TSC, is even more upregulated in response to rapamycin treatment, such regulation has been recently reported in vitro using TSC2-1cells [9]. Moreover, the authors show that miR-21 inhibition represses the tumor growth of TSC2-/xenografts in vivo and that combined miR-21 inhibition with rapamycin treatment may increase survival of mice and inhibit the tumor regrowth after rapamycin cessation [9].

Here we show for the first time the effect of long-lasting (6-12 months) rapamycin administration in TSC patients on miR-21-5p expression in vivo, in the blood serum. Our data show that rapamycin treatment elevates miR-21-5p levels in patients' serum. Given that miR-21 is hypothesized to promote adaptation and survival of TSC tumor cells, it seems that its upregulation may contribute to the therapeutic response to rapamycin in TSC and may be responsible for the partial efficacy of the therapy. Our data confirm the previous reports suggesting that miR-21 is a good target for rapamycin combined therapy of tumors associated with TSC.

\section{Acknowledgements}

This study was funded by statutory grant of the Children's Memorial Health Institute no. S132/2013 financed by the Ministry of Science and Higher Education, grant EPIMARKER of the Polish National Center for Research and Development no. STRATEGMED3/306306/4/2016 and NCN OPUS grant 2014/15/B/NZ3/01054 for MDz. 


\section{Disclosure}

\section{The authors report no conflict of interest.}

\section{References}

1. Bissler JJ, McCormack FX, Young LR, Elwing JM, Chuck G, Leonard JM, Schmithorst VJ, Laor T, Brody AS, Bean J, Salisbury S, Franz DN. Sirolimus for angiomyolipoma in tuberous sclerosis complex or lymphangioleiomyomatosis. N Engl J Med 2008; 358: 140-151

2. Franz DN, Belousova E, Sparagana S, Bebin EM, Frost MD, Kuperman R, Witt O, Kohrman MH, Flamini JR, Wu JY, Curatolo P, de Vries PJ, Berkowitz N, Niolat J, Jozwiak S. Long-term use of everolimus in patients with tuberous sclerosis complex: final results from the EXIST-1 study. PLoS One 2016; 11: e0158476.

3. Franz DN, Leonard J, Tudor C, Chuck G, Care M, Sethuraman G, Dinopoulos A, Thomas G, Crone KR. Rapamycin causes regression of astrocytomas in tuberous sclerosis complex. Ann Neurol 2006; 59: 490-498.

4. Henske EP, Jozwiak S, Kingswood JC, Sampson JR, Thiele EA. Tuberous sclerosis complex. Nat Rev Dis Primers 2016; 2: 16035.

5. Jozwiak S, Mandera M, Mlynarski W. Natural history and current treatment options for subependymal giant cell astrocytoma in tuberous sclerosis complex. Semin Pediatr Neurol 2015; 22: 274-281.

6. Jozwiak S, Nabbout R, Curatolo P, participants of the TSC Consensus Meeting for SEGA and Epilepsy Management. Management of subependymal giant cell astrocytoma (SEGA) associated with tuberous sclerosis complex (TSC): Clinical recommendations. Eur J Paediatr Neurol 2013; 17: 348-352.

7. Kotulska K, Borkowska J, Roszkowski M, Mandera M, Daszkiewicz P, Drabik K, Jurkiewicz E, Larysz-Brysz M, Nowak K, Grajkowska W, Domanska-Pakiela D, Jozwiak S. Surgical treatment of subependymal giant cell astrocytoma in tuberous sclerosis complex patients. Pediatr Neurol 2014; 50: 307-312.

8. Kumarswamy R, Volkmann I, Thum T. Regulation and function of miRNA-21 in health and disease. RNA Biol 2011; 8: 706-713.

9. Lam HC, Liu HJ, Baglini CV, Filippakis H, Alesi N, Nijmeh J, Du H, Lope AL, Cottrill KA, Handen A, Asara JM, Kwiatkowski DJ, Ben-Sahra I, Oldham WM, Chan SY, Henske EP. Rapamycin-induced miR-21 promotes mitochondrial homeostasis and adaptation in mTORC1 activated cells. Oncotarget 2017; 8: 6471464727.

10. Li J, Kim SG, Blenis J. Rapamycin: one drug, many effects. Cell Metab 2014; 19: 373-379.

11. Northrup H, Krueger DA, International Tuberous Sclerosis Complex Consensus. Tuberous sclerosis complex diagnostic criteria update: recommendations of the 2012 linternational Tuberous Sclerosis Complex Consensus Conference. Pediatr Neurol 2013; 49: 243-254.

12. Roth J, Roach ES, Bartels U, Jozwiak S, Koenig MK, Weiner HL, Franz DN, Wang HZ. Subependymal giant cell astrocytoma: diagnosis, screening, and treatment. Recommendations from the International Tuberous Sclerosis Complex Consensus Conference 2012. Pediatr Neurol 2013; 49: 439-444.
13. Sadowski K, Kotulska K, Jozwiak S. Management of side effects of mTOR inhibitors in tuberous sclerosis patients. Pharmacol Rep 2016; 68: 536-542.

14. Sadowski K, Kotulska K, Schwartz RA, Jozwiak S. Systemic effects of treatment with mTOR inhibitors in tuberous sclerosis complex: a comprehensive review. J Eur Acad Dermatol Venereol 2016; 30: 586-594.

15. Trelinska J, Dachowska I, Baranska D, Stawiski K, Kotulska K, Fendler W, Jozwiak S, Mlynarski W. Maintenance therapy with everolimus for subependymal giant cell astrocytoma in patients with tuberous sclerosis (the EMINENTS study). Pediatr Blood Cancer 2017; 64.

16. Trelinska J, Dachowska I, Kotulska K, Baranska D, Fendler W, Jozwiak S, Mlynarski W. Factors affecting response to everolimus therapy for subependymal giant cell astrocytomas associated with tuberous sclerosis. Pediatr Blood Cancer 2015; 62: 616-621.

17. Trindade AJ, Medvetz DA, Neuman NA, Myachina F, Yu J, Priolo C, Henske EP. MicroRNA-21 is induced by rapamycin in a model of tuberous sclerosis (TSC) and lymphangioleiomyomatosis (LAM). PLoS One 2013; 8: e60014.

18. van Scheppingen J, Iyer AM, Prabowo AS, Muhlebner A, Anink JJ, Scholl T, Feucht M, Jansen FE, Spliet WG, Krsek P, Zamecnik J, Buccoliero AM, Giordano F, Genitori L, Kotulska K, Jozwiak S, Jaworski J, Liszewska E, van Vliet EA, Aronica E. Expression of microRNAs miR21, miR146a, and miR155 in tuberous sclerosis complex cortical tubers and their regulation in human astrocytes and SEGA-derived cell cultures. Glia 2016; 64: 1066-1082. 